\title{
Correction to: An Acceleration of Improved Segmentation Methods for Dermoscopy Images Using GPU
}

\author{
Pawan Kumar Upadhyay and Satish Chandra
}

\section{Correction to:}

Chapter "An Acceleration of Improved Segmentation Methods for Dermoscopy Images Using GPU" in:
A. Khare et al. (eds.), Recent Trends in Communication, Computing, and Electronics, https://doi.org/10.1007/978-981-13-2685-1_25

The book was inadvertently published with chapter author's incorrect family name. This information has been updated from "Pawan Kumar Updhyay" to "Pawan Kumar Upadhyay" in the initially published version of chapter " 25 ". 